from the face by electric trains, sent to the surface by conveyer belt and lowered to the works at the foot of the mountain by cable hoists. The ore mine has four electric power stations and a central aircompressing station. There is an electric sub-station underground. The nearest centre to the new works is Nalchik, capital of Kabardino-Balkaria.

\section{Detection of Toxic Gases}

WE have received a copy of Leaflet No. 12, "Methods for the Detection of Toxic Gases in Industry: Organic Halogen Compounds" (H.M. Stationery Office, $1940.2 d$. net). Ten substances are covered, including tetrachloroethane, pentachloroethane and carbon tetrachloride. One of the most toxic of the group is tetrachloroethane. The method of detection is by the use of a special lamp burning pure alcohol in a supply of the air under test. The halides are decomposed and react with a small copper screw in the nozzle of the lamp, giving a green coloration to the flame.

\section{Marie-Alfred Cornu, For.Mem.R.S. (I84I-I902)}

ON March 6 occurs the centenary of the birth of the distinguished French physicist, Marie-Alfred Cornu, who for thirty-five years held the chair of physics at the Ecole Polytechnique and who in 1896 was elected president of the Paris Academy of Sciences. Born at Chateauneuf, near Orleans, he had a brilliant career as a student at the Ecole Polytechnique and the Ecole des Mines, and was made a professor at the former at the age of twentysix. His investigations carried out in the next ten or fifteen years raised him to the highest rank of experimentalists. Using Fizeau's methods he redetermined the velocity of light; with Baille, in the cellar of the Ecole Polytechnique, he re-determined the density of the earth, and among his memoirs of this time were some on the theory of electrostatics in which he explained the potential theory of Gauss and Green, then little known in France. His later work included valuable researches in spectroscopy. He was admitted a member of the Paris Academy of Sciences in 1878 as successor to A. C. Becquerel, and in the same year received the Lacaze Medal, and also the Rumford Medal of the Royal Society. In his own country he served on the Bureau des Longitudes, and as president of the International Commission of Weights and Measures. He was a foreign member of the Royal Society, and an associate of the Royal Astronomical Society. As Rede Lecturer at Cambridge in 1899, he discussed "The Wave Theory of Light and its Influence on Modern Physics". He was not only a successful experimentalist and a leader in scientific thought, but also a great teacher. He died on April 11, 1902. Three years later the French Physical Society struck a medal in his honour.

\section{The Night Sky in March}

THE shortening night reaches equality with the day at the spring equinox, March 21d. 0h. U.T. The moon is full on March 13 and new on March 27. A partial lunar eclipse occurs at the full and an annular eclipse of the sun at the time of new moon, but both eclipses are invisible from Great Britain. A notable occultation takes place on March 5, when both the disappearance and reappearance of $\alpha$ Tauri (Aldebaran) can be favourably observed subject to weather. As seen from Greenwich, the disappearance of the star behind the moon's unilluminated edge (moon near first quarter) is at $19 \mathrm{~h} .16 \cdot 1 \mathrm{~m}$. at position angle $108^{\circ}$ from the north point of the moon's image; the subsequent reappearance is at $20 \mathrm{~h}$. $29 \cdot 1 \mathrm{~m}$. at $242^{\circ}$. On March $8, \lambda$ Geminorum is also occulted, the disappearance seen from Greenwich being at $2 \mathrm{Jh} .20 .4 \mathrm{~m}$. at position angle $97^{\circ}$ (Add 1 hour to all these times to read in Summer Time.)

of the planets visible this month, Jupiter and its close companion, Saturn, are in the western sky at sunset; they are not far from the moon's slender crescent on March 3 and 30. Mars continues as an early morning star, in the constellation of Sagittarius. The planet is moving about 3 minutes of Right Ascension per day eastwards amongst the stars. Venus and Mercury are now stars of the dawn, being in conjunction with each other on March 3 at $13 \mathrm{~h}$. Mercury reaches greatest western elongation $\left(28^{\circ}\right)$ on March 25 , but Venus is drawing towards the sun's place until superior conjunction on April 19. In mid-March, Sirius souths about 1 hour after sunset.

As night sets in, the bright stars of the familiar winter constellation are declining westwards. Amongst the less spectacular constellations east of the meridian is Coma Berenices. This constellation contains a loose cluster of stars which, about March 15, comes to the southern meridian at $2 \mathrm{~h}$. summer time at an altitude of $65^{\circ}$. East of this cluster is the position of the north galactic pole. A long-exposure photograph (200 minutes) taken with the 100 -inch reflecting telescope at Mount Wilson "records fully as many recognizable nebulæ as stars" (Hubble). The farthest of these nebulæ recorded on the photograph are thought to be at an average distance of the order of 500 million light years. Thus in the general direction of the galactic polesunobscured by the vast gas and dust clouds of our stellar system-we look out into remotest space.

\section{Announcements}

ON medical advice, Sir Edwin Butler, formerly director of the Imperial Mycological Institute, has resigned from the secretaryship of the Agricultural Research Council.

Dr. Franz Verdoorn, editor of Chronica Botanica, has been appointed research associate in the Farlow Herbarium, Harvard University.

THE Rockefeller Foundation has agreed to continue until the end of 1941 its grant of $£ 1,200$ a year for research in cellular physiology at the Molteno Institute, University of Cambridge, under the direction of Prof. D. Keilin.

IN 1938 there were 15,111 cases of smallpox in the United States. Of these, 14,106 occurred in the States north of Ohio and west of Mississipi, where vaccination is not compulsory. 